\title{
Interleukin-6: the missing element of the neurocognitive deterioration in schizophrenia? The focus on genetic underpinnings, cognitive impairment and clinical manifestation
}

\author{
Dorota Frydecka • Błażej Misiak • Edyta Pawlak-Adamska • Lidia Karabon • \\ Anna Tomkiewicz $\cdot$ Pawel Sedlaczek · Andrzej Kiejna · Jan Aleksander Beszłej
}

Received: 18 April 2014/ Accepted: 2 September 2014/Published online: 12 September 2014

(c) The Author(s) 2014. This article is published with open access at Springerlink.com

\begin{abstract}
The influence of the immune system deregulation on the risk of schizophrenia is increasingly recognized. The aim of this study was to assess the influence of serum interleukin-6 (IL-6) level together with the polymorphism in its gene (IL6 -174G/C) and high sensitivity C-reactive protein (hSCRP) levels on clinical manifestation and cognition in schizophrenia patients. We recruited 151 patients with schizophrenia and 194 healthy control subjects. Psychopathology was evaluated using Operational Criteria for Psychotic Illness checklist, Positive and Negative Syndrome Scale (PANSS) and Scales for Assessment of Positive and Negative Symptoms. Cognitive performance in schizophrenia patients was assessed using following tests: Rey Auditory Verbal Learning Test, Trail Making Test, Verbal Fluency Tests, Stroop and subscales
\end{abstract}

D. Frydecka $(\varangle) \cdot$ B. Misiak · A. Kiejna · J. A. Beszłej Department of Psychiatry, Wroclaw Medical University,

10 Pasteur Street, 50-367 Wrocław, Poland

e-mail: dfrydecka@gmail.com

B. Misiak

Department of Genetics, Wroclaw Medical University,

1 Marcinkowski Street, 50-368 Wrocław, Poland

E. Pawlak-Adamska $\cdot$ L. Karabon · A. Tomkiewicz Laboratory of Immunopathology, Department of Experimental Therapy, Institute of Immunology and Experimental Therapy, Polish Academy of Sciences, Weigla 12, 51-114 Wrocław, Poland

\section{Karabon}

Department of Forensic Medicine, Wroclaw Medical University,

Mikulicza-Radeckiego 4, 50-368 Wrocław, Poland

\section{P. Sedlaczek}

1st Department and Clinic of Gynaecology and Obstetrics,

Wroclaw Medical University, Chałubińskiego 3,

50-368 Wrocław, Poland from Wechsler Adults Intelligence Scale-R-Pl (Similarities, Digit Symbol Coding, Digit Span Forward and Backward). Serum IL-6 and hsCRP levels were significantly higher in schizophrenia patients in comparison with healthy controls. Both hsCRP and IL-6 levels were associated with insidious psychosis onset, duration of illness and chronic schizophrenia course with deterioration. After adjustment for age, education level, number of years of completed education, illness duration, total PANSS score, depression severity and chlorpromazine equivalent, there was still a positive association between IL- 6 and hsCRP levels and worse cognitive performance. The IL6 -174G/C polymorphism did not influence IL-6 level, but it was associated with the severity of positive symptoms. Our results suggest that elevated IL-6 levels may play the role in cognitive impairment and serve as potential inflammatory biomarker of deterioration in schizophrenia.

Keywords Interleukin-6 - C-reactive protein - Gene polymorphism $\cdot$ Cognition $\cdot$ Schizophrenia $\cdot$ Inflammation

\section{Introduction}

Interleukin-6 (IL-6) is a multifactorial cytokine that is implicated in hematopoiesis, metabolic control, bone metabolism and nociceptive regulation [1]. Notably, IL-6 has been implicated in the pathophysiology of schizophrenia. The first meta-analysis of cytokine alterations in schizophrenia patients provided that IL-6 level is increased in this group of patients [2]. These findings are in line with animal models showing that IL-6 promotes the survival of catecholaminergic neurones as well as stimulates serotonergic and dopaminergic transmission in the hippocampus and prefrontal cortex [3]. In the recent meta-analysis by 
Miller et al. [4], IL-6 was found to serve as a state marker of schizophrenia, which is increased in first-episode psychosis and acutely relapsed patients, and prone to normalize with antipsychotic treatment. Interestingly, emerging evidence indicates that IL-6 level is increased already in subjects with at-risk mental state (ARMS) and might be a marker of transition from ARMS to schizophrenia [5].

There is scarcity of studies looking into clinical correlates of IL-6 alterations in schizophrenia. It has been found that treatment-resistant schizophrenia is associated with elevated level of IL-6 [6]. In addition, Ganguli et al. [7] provided a positive correlation between IL- 6 level and illness duration. However, the association between plasma IL-6 level and psychopathological manifestation of schizophrenia together with cognitive functioning among this group of patients has not been investigated so far.

There are also studies reporting the association between the $-174 \mathrm{G} / \mathrm{C}$ polymorphism in the IL-6 gene (ILO) and schizophrenia. This polymorphism lies in the promoter region that accounts for transcription induced by viruses, second messengers or other cytokines [8] and leads to decrease in the IL6 gene expression [9]. Although one study found that the IL6-174 G/C gene polymorphism influences the risk of schizophrenia [10] and another study that found a trend toward a significant difference in genotype distribution and allele frequency between paranoid schizophrenia patients and healthy controls [11], other authors, including our group [12], have not confirmed this association [13-15]. There is also one study by Zakharyan et al. [10] looking at the relationship between the IL6 -174G/C polymorphism and plasma IL-6 levels in schizophrenia patients. In this study, it was shown that the IL6 -174G/C polymorphism is associated with increased plasma IL-6 in schizophrenia patients and constitutes a risk factor for the disorder.

Extensive evidence suggests that IL-6 may influence cognitive functioning. Studies on healthy adults indicate that IL-6 plasma level negatively correlates with semantic fluency [16], auditory recognition memory, attention, working memory, as well as executive functions [17]. Other studies performed in older subjects have reported a positive association between plasma IL-6 level and impairment in a considerable number cognitive domains including working memory [18], executive functioning [19], processing speed and attention [20], orientation, immediate verbal recall, delayed recall or psychomotor speed [21], semantic fluency and prospective memory [22]. Finally, there has been an inverse relationship between plasma IL-6 level and verbal memory in patients with depression [23].

Cognitive functioning is moderately to severely impaired in most important domains including attention, memory, reasoning and processing speed in schizophrenia patients [24]. However, cognition is sparsely addressed in studies investigating immune and inflammatory aspects of schizophrenia. There is only one study showing that a subclinical inflammation, manifested in elevated level of C-reactive protein (CRP), is associated with poorer $\operatorname{cog}$ nitive performance [25].

Interestingly, growing evidence from clinical studies with nonsteroidal anti-inflammatory agents points to the favorable effects of immunomodulatory therapy in schizophrenia, in particular in an early stage of the disorder [26]. Moreover, it has also been shown that anti-inflammatory add-on treatment may not only have beneficial effects with respect to symptoms severity as shown by recent meta-analyses [27, 28], but in particular attenuates cognitive impairment among patients with schizophrenia [29].

This study aimed at bridging important gaps in IL-6 research in schizophrenia patients, including the association between the IL6 -174G/C polymorphism and serum IL-6 level, the influence of IL-6 level alterations on clinical and psychopathological manifestation, as well as the relationship between IL-6 production and cognitive functioning among patients with schizophrenia. Our main hypothesis was that the $G$ allele of the IL6 -174G/C polymorphism could predict the higher expression of IL-6, while the higher IL-6 level could be a risk factor for progressive cognitive decline observed in schizophrenia.

\section{Materials and methods}

\section{Subjects}

We recruited 151 patients with schizophrenia (82 females and 69 males of mean age $37.84 \pm 11.56$ ), including individuals during a recovery from acute relapse or stable outpatients and 194 controls (91 females and 103 males of mean age $39.22 \pm 11.95$ ) (Table 1). All participants were of Caucasian origin and came from the same geographic area-Lower Silesia. Study protocol was approved by the Wroclaw Medical University Ethics Committee and all subjects gave an informed consent after the nature of the procedures had been fully explained. The study was performed in accordance with the latest version of the Declaration of Helsinki. There were following exclusion criteria in the patients group: history of traumatic brain injury, neurologic disorders, severe physical health impairments and comorbid substance addiction (with exception of nicotine). A diagnosis of schizophrenia was established by the same two senior-board psychiatrists according to DSM-IV criteria and based on individual 
Table 1 General characteristics of schizophrenia patients and healthy control subjects

\begin{tabular}{llll}
\hline $\begin{array}{l}\text { Demographic and clinical } \\
\text { variables }\end{array}$ & $\begin{array}{l}\text { SCH } \\
n=151\end{array}$ & $\begin{array}{l}\text { HC } \\
n=194\end{array}$ & $p$ value $^{\mathrm{a}}$ \\
\hline Age (years) & $37.84(11.56)$ & $39.22(11.95)$ & 0.28 \\
Female (\%) & $54 \%$ & $47 \%$ & 0.30 \\
Education (years) & $12.67(3.80)$ & $13.67(3.35)$ & 0.09 \\
Ethnicity (Caucasian) & $100 \%$ & $100 \%$ & 1.00 \\
Disease duration (years) & $12.24(9.22)$ & - & - \\
$\begin{array}{l}\text { Number of previous } \\
\text { episodes }\end{array}$ & $5.47(4.66)$ & - & - \\
\hline
\end{tabular}

$S C H$ schizophrenia patients, $H C$ healthy control subjects

a ANOVA test

interviews, clinical observation and medical records. Lifetime psychopathology of schizophrenia was assessed using Operational Criteria for Psychotic Illness (OPCRIT) checklist [30]. Additionally, general appraisal of the course of disorder has been conducted according to the OPCRIT guidelines dividing patients to the following categories: Single episode with good recovery, multiple episodes with good recovery between, multiple episodes with partial recovery between, continuous chronic illness and continuous chronic illness with deterioration [30]. It has been assessed based on the interpersonal, social and vocational functioning in comparison with the premorbid level of functioning. All of the patients have been medicated on the day of the assessment. The mean duration of treatment was $12.24 \pm 12.24$ years. The majority of patients were treated with the second generation antipsychotic drugs $(14.58 \%$ olanzapine, $27.08 \%$ risperidone, $12.50 \%$ quetiapine, $21.87 \%$ clozapine, $11.45 \%$ ziprasidone, $2.08 \%$ aripiprazole and $2.08 \%$ sertindole), while the rest of the patients were treated with the first generation antipsychotics (2.08\% chlorpromazine, $1.04 \%$ perazine, $1.04 \%$ zucklopenthixol and $4.16 \%$ haloperidol). The mean value of daily chlorpromazine (CPZ) equivalent dose was $571.84 \pm 401.98 \mathrm{mg} /$ day [31].

All healthy controls had negative present, past and family history of psychiatric illness. Patients with schizophrenia were excluded if they had current infections, allergies, severe physical health illness, present and past history of autoimmune disorders as well as abnormal blood and urine tests such as hemoglobin, hematocrit, liver transaminases, serum electrolytes, blood urea and creatinine. Current psychopathology status, cognitive performance and the IL6 -174 G/C polymorphism were assessed in the whole study group, while serum high sensitivity CRP (hsCRP) and IL-6 levels were measured in a randomly chosen subgroup of 88 schizophrenia patients and 88 healthy controls (Table 2).
Assessment of psychopathology and cognitive functions

Symptoms severity on the day of assessment was evaluated using Positive and Negative Syndrome Scale (PANSS), Scale for Assessment of Positive Symptoms (SAPS) and Scale for Assessment of Negative Symptoms (SANS).

Cognitive performance in schizophrenia patients was assessed using Rey Auditory Verbal Learning Test (RAVLT) [32], Trail Making Tests (TMT-A and TMT-B) [33], Verbal Fluency Tests FAS letters [34] and Supermarket [35], Stroop test [36] as well as selected Wechsler Adults Intelligence Scale (WAIS-R-Pl) subtests: Digit Symbol Coding Test, Digit Span Forward and Backward and Similarities.

\section{Genotyping}

Genomic DNA was obtained from peripheral blood leukocytes (from whole frozen blood) using the QIAamp DNA Blood Mini Kit (Qiagen GmbH, Hilden, Germany). The IL6 -174G/C polymorphism was genotyped using the PCR with sequence specific primers technique (PCR-SSP) with the use of PCTYGEN kit (One Lambda, Canoga Park, USA). PCR products were visualized on $2 \%$ agarose gel.

\section{IL-6 and hsCRP measurement}

The serum samples of 88 schizophrenia patients and 88 healthy subjects were stored in aliquots at $-80{ }^{\circ} \mathrm{C}$. Serum concentrations were measured blinded for case and control status. Serum hsCRP was measured with the use of the C-Reactive Protein Extended Range (RCRP) method on the Dimension ${ }^{\circledR}$ clinical chemistry system (Siemens Healthcare Diagnostics Inc., Newark USA). Serum levels of IL-6 were measured using a commercially available human IL-6 Immunoassay (Quantikine ${ }^{\circledR}$ ELISA, R\&D Systems, Inc., Minneapolis, MN), according to the manufacturer's instructions. Manual reference data for intraassay and inter-assay coefficients of variance is 1.6-4.2 and $3.3-6.4 \%$, respectively.

\section{Statistics}

The differences in serum levels of IL- 6 between subjects with different $I L 6-174 \mathrm{G} / \mathrm{C}$ genotypes and allele carriers in schizophrenia patients and healthy controls were compared using Kruskal-Wallis test and Mann-Whitney $U$ test. Demographic and clinical data with respect to the IL6 -174G/C polymorphism among patients with schizophrenia were compared using ANOVA test (BMI, age, pack-year, chlorpromazine equivalent, years of education, disease duration and number of previous episodes) and $\chi^{2}$ 


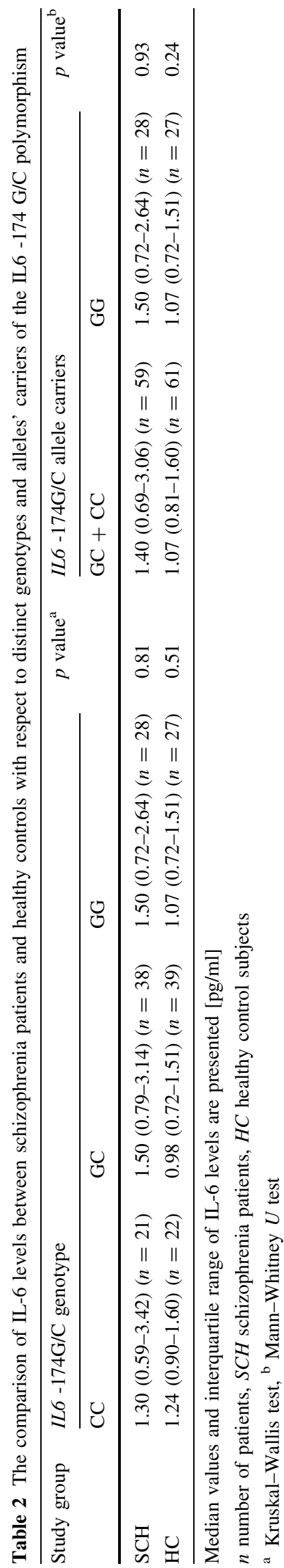

test (gender, education, family history of schizophrenia and course of the disorder). Cognitive performance and psychopathological manifestation with respect to the IL6 -174G/C polymorphism was compared using ANOVA test; however, in case of RAVLT (recognition subtest), Kruskal-Wallis test was used due to lack of homogeneity of variances assessed by Levene's test. Correlations between clinical variables and cognitive functioning with serum IL-6 and hsCRP levels were assessed using Spearman's rank correlations (Spearman's rho). Due to multiple testing of correlations between clinical variables or $\operatorname{cog}$ nitive functioning with serum IL- 6 and hsCRP, Bonferroni correction was applied to the level of significance. The association between immune markers and cognitive functioning was performed using linear regression analysis adjusting for age, education level, number of years of completed education, illness duration, total PANSS score, depression severity and chlorpromazine equivalent. Differences were considered as statistically significant if the $p$ value was $<0.05$. All analyses were performed using the Statistical Package for Social Sciences (SPSS) version 20.

\section{Results}

The comparison of genotype distribution and allele frequency of the IL6 -174G/C polymorphism between schizophrenia patients and healthy controls was presented in our previous paper [12]. There was no significant association between the IL6 -174G/C polymorphism and the risk of schizophrenia.

Serum IL-6 was significantly higher in schizophrenia patients in comparison with healthy controls (median: $1.4 \pm 2.23$ and $1.07 \pm 0.77$, respectively, $p=0.049$ ). Similarly, serum hsCRP was significantly higher in schizophrenia patients in comparison with healthy controls (median: $3.30 \pm 3.7$ and $2.30 \pm 1.6$, respectively, $p<0.001)$. There was no association between the IL6 -174G/C polymorphism and serum IL-6 in schizophrenia patients and healthy controls (Table 2). Similarly, there was no significant difference in demographics and general clinical variables with respect to the $I L 6-174 \mathrm{G} / \mathrm{C}$ polymorphism in schizophrenia patients (Table 3). We found no significant difference between the variables that may influence the relationship between the IL6 -174G/C polymorphism and IL-6 levels, such as age, gender, chlorpromazine equivalent, illness duration, cigarette smoking and BMI across the IL6 -174G/C genotypes (Table 3).

Finally, this polymorphism was not associated with the psychopathological manifestation assessed with OPCRIT (data not shown) and psychopathological scales nor with cognitive functioning (Table 3). However, the comparison of positive symptoms severity assessed using SAPS 
Table 3 Demographic and clinical characteristics of schizophrenia patients with respect to the IL6 $-174 \mathrm{G} / \mathrm{C}$ polymorphism

Mean and standard deviation values are presented

$n$ number of patients

a ANOVA test

b $\chi^{2}$ test

c Pack-year Index was calculated as the number of cigarettes packs per 1 day multiplied by number of years smoked and divided by 20

\begin{tabular}{|c|c|c|c|c|}
\hline \multirow[t]{2}{*}{ Demographic and clinical variables } & \multicolumn{3}{|c|}{ The IL6 $-174 \mathrm{G} / \mathrm{C}$ genotype } & \multirow[t]{2}{*}{$p$ value $^{\mathrm{a}}$} \\
\hline & $\mathrm{CC}(n=39)$ & $\mathrm{GC}(n=72)$ & GG $(n=40)$ & \\
\hline Age (years) & $39.90(10.7)$ & $37.47(9.7)$ & $40.20(10.6)$ & 0.18 \\
\hline Female $(\%)$ & $52 \%$ & $43 \%$ & $44 \%$ & $0.56^{\mathrm{b}}$ \\
\hline Education (\%) & & & & $0.68^{\mathrm{b}}$ \\
\hline Primary & $13 \%$ & $7 \%$ & $8 \%$ & \\
\hline Vocational & $22 \%$ & $20 \%$ & $20 \%$ & \\
\hline Secondary & $52 \%$ & $47 \%$ & $60 \%$ & \\
\hline Higher & $13 \%$ & $26 \%$ & $12 \%$ & \\
\hline Education (years) & $12.30(3.77)$ & $12.89(3.95)$ & $11.92(4.50)$ & 0.62 \\
\hline Disease duration (years) & $12.77(8.73)$ & $11.32(9.94)$ & $13.13(9.10)$ & 0.63 \\
\hline Number of previous episodes & $5.38(3.12)$ & $4.64(3.87)$ & $6.94(6.42)$ & 0.25 \\
\hline $\begin{array}{l}\text { Family history of schizophrenia in } \\
\text { first or second degree relative }(\%)\end{array}$ & $8.06 \%$ & $19.36 \%$ & $6.45 \%$ & $0.30^{\mathrm{b}}$ \\
\hline $\begin{array}{l}\text { Chronic course of disorder with } \\
\text { deterioration }(\%)\end{array}$ & $7.26 \%$ & $16.93 \%$ & $8.06 \%$ & $0.81^{\mathrm{b}}$ \\
\hline Chlorpromazine equivalent & $530.25(299.04)$ & $604.40(418.13)$ & $557.53(469.30)$ & 0.79 \\
\hline Body mass index (BMI) $\left(\mathrm{kg} / \mathrm{m}^{2}\right)$ & $26.01(3.52)$ & $27.11(5.10)$ & $28.63(8.73)$ & 0.46 \\
\hline Pack-year Index ${ }^{c}$ & $6.55(9.48)$ & $10.51(16.80)$ & $10.75(10.24)$ & 0.69 \\
\hline
\end{tabular}

showed significant differences between homozygotes $(p=0.027)$ and trend level differences when assessed using PANSS $(p=0.07)$. Indeed, the $-174 \mathrm{GG}$ homozygotes had higher severity of positive symptoms in comparison with the $-174 \mathrm{CC}$ patients (data not shown).

Serum IL-6 positively correlated with hsCRP in schizophrenia patients $(r=0.57, p<0.001)$ and healthy controls $(r=0.52, p<0.001)$. There was no significant correlation between age and hsCRP or IL-6 levels neither in schizophrenia patients $(r=0.11, \quad p=0.31$ and $r=0.26, p=0.22$, respectively) nor in healthy controls ( $r=0.054, p=0.60$ and $r=0.11, p=0.39$ ).

Correlations between hsCRP or IL-6 levels and clinical variables in schizophrenia subjects are provided in Table 4. Indeed, hsCRP level was negatively associated with the scores of the majority of RAVLT subtests. However, there was a positive correlation between hsCRP level and chlorpromazine equivalent ( $r=0.32, p=0.009$ ).

Serum level of IL- 6 was correlated with worse cognitive performance on TMT-A $(r=0.38, p=0.001)$ and TMT-B ( $r=0.48, p=0.001)$, Stroop test (congruent) $(r=0.27$, $p=0.024)$ and Stroop test (incongruent) $(r=0.34$, $p=0.005)$, Verbal Fluency (FAS total score) $(r=-0.31$, $p=0.011)$, Forward Digit Span test $(r=-0.27$, $p=0.026)$ and Digit Symbol Coding test $(r=-0.45$, $p<0.001)$. Both IL-6 and hsCRP serum levels were associated with worse performance on the majority of RAVLT subtests (Table 5).

The correlations of IL-6 level with cognitive performance in TMT tasks, RAVLT subtests (third, fourth and fifth immediate recall) and Digit Symbol Coding test, as well as the correlation of hsCRP with RAVLT subtests (first and second immediate recall) remained significant after adjustment for multiple testing ( $p<0.00147$ ) (Table 5).

Chlorpromazine equivalent was significantly associated with higher IL-6 level ( $r=0.57, p<0.001)$, even after the application of Bonferroni correction $(p<0.00147)$. Interestingly, longer illness duration predicted higher IL-6 levels ( $r=0.30, p=0.008$ ). Additionally, there was a higher level of serum IL-6 among patients with schizophrenia characterized by chronic course with deterioration in comparison with the schizophrenic patients with multiple episodes with good or partial recovery or even with chronic course; however, without marked deterioration of functioning ( $p=0.01$ ) (Fig. 1).

After adjustment for age, education level, number of years of completed education, illness duration, total PANSS score, depression severity in PANSS and chlorpromazine equivalent, there was a trend level association of hsCRP and statistically significant association of IL-6 with lower scores on immediate recall span assessed by RAVLT (total score summed across 1st through fifth trial) ( $\beta=-0.1395 \% \mathrm{CI}-0.26-0.01, p=0.06$; $\beta=-0.05,95 \% \mathrm{CI}-0.10-0.01, p=0.04$, respectively). Additionally, higher IL-6 levels predicted worse cognitive performance on Digit Symbols Coding test $(\beta=-0.62$, $95 \% \mathrm{CI}-0.11-0.16, p=0.009)$ (Table 6).

\section{Discussion}

The influence of the immune system deregulation on the risk of schizophrenia has been reported for years now; however, the association between CRP and IL-6 with 
Table 4 Cognitive performance and psychopathological manifestation with respect to the IL6-174G/C polymorphism

\begin{tabular}{|c|c|c|c|c|}
\hline & \multicolumn{3}{|c|}{ the IL6 $-174 \mathrm{G} / \mathrm{C}$ genotype } & \multirow[t]{2}{*}{$p$ value $^{\mathrm{a}}$} \\
\hline & $\mathrm{CC}(n=39)$ & $\mathrm{GC}(n=72)$ & $\mathrm{GG}(n=40)$ & \\
\hline PANSS—positive symptoms & $17,17.99(6.23)$ & $18,19.74(7.72)$ & $23,21.76(5.95)$ & 0.24 \\
\hline PANSS—negative symptoms & $24,23.09(7.57)$ & $21,21.89(8.52)$ & $24,25.28(7.85)$ & 0.28 \\
\hline PANSS—general symptoms & 39, $39.74(7.89)$ & $38,39.79(11.28)$ & $43,43.64(11.66)$ & 0.53 \\
\hline PANSS—total score & $82,80.78(17.68)$ & $75,81.42(24.96)$ & $87,90.22(23.65)$ & 0.36 \\
\hline PANSS—depression item & $1,1.77(1.10)$ & $1,1.72(1.01)$ & $1,1.70(1.17)$ & 0.97 \\
\hline SAPS & $26,19.71(15.93)$ & $25,31.32(21,47)$ & $37,38.48(20.37)$ & 0.11 \\
\hline SANS & $37,41.39(19.44)$ & $31,36.53(21.39)$ & $45,47.64(21.11)$ & 0.12 \\
\hline TMT, part A & $45,48.80(27.5)$ & $41,50.46(48.3)$ & 42, $39.98(29.0)$ & 0.98 \\
\hline TMT, part B & $109,136.58(99.0)$ & $101,140.17(113.7)$ & $110,101.73(79.3)$ & 0.95 \\
\hline Stroop, congruent & 37, $40.71(12.9)$ & 40, $37.08(22.0)$ & $41,40.53(17.7)$ & 0.49 \\
\hline Stroop, incongruent & $81.50,87.75(35.8)$ & $72,80.04(35.6)$ & $75,81.33(39.7)$ & 0.70 \\
\hline RAVLT, first immediate recall & $4,3.25(1.93)$ & $4.50,4.35(1.87)$ & $4,4.55(2.38)$ & 0.79 \\
\hline RAVLT, second immediate recall & $6,6.39(2.59)$ & $7,6.32(2.45)$ & $6,7.39(2.62)$ & 0.78 \\
\hline RAVLT, third immediate recall & $8,7.39(2.62)$ & $7,7.14(2.43)$ & $8,7.27(2.98)$ & 0.88 \\
\hline RAVLT, fourth immediate recall & $9,8.30(2.98)$ & $8,8.43(2.63)$ & $9,8.95(3,03)$ & 0.93 \\
\hline RAVLT, fifth immediate recall & $9,8.78(3.60)$ & $9,8,84(2.30)$ & $9,9.45(3.00)$ & 0.70 \\
\hline RAVLT, inference & $8,7.32(3,03)$ & $7,7.43(2.91)$ & $7,7.60(2.99)$ & 0.96 \\
\hline RAVLT, delayed recall & 7, $6.00(3.49)$ & $6.5,6.65(2.44)$ & $6,6.84(3.10)$ & 0.74 \\
\hline RAVLT, recognition & $11,9.41(4.68)$ & $10,9.90(3.48)$ & $10,9.24(3.60)$ & $0.48^{\mathrm{b}}$ \\
\hline Verbal fluency, F words & $5,5.91(3.76)$ & $7,7.22(3.70)$ & $6,5.43(4.16)$ & 0.29 \\
\hline Verbal fluency, A words & $5,6.13(3.47)$ & $6,7.35(3.85)$ & $6,5.41(3.30)$ & 0.11 \\
\hline Verbal fluency, S words & $8,8.52(4.71)$ & $9,8.19(3.25)$ & $7,7.91(3.38)$ & 0.38 \\
\hline Verbal fluency, $\mathrm{K}$ words & $10,10.43(4.94)$ & $12,12.32(4.61)$ & $10,10.59(4.23)$ & 0.18 \\
\hline Verbal fluency, supermarket & $16,17.52(7.98)$ & $15,15.70(5.85)$ & $13,15.14(7.19)$ & 0.35 \\
\hline Forward digit span & $6,6.14(1.78)$ & $6,6,20(1.96)$ & $6,6.08(1.89)$ & 0.90 \\
\hline Backward digit span & $5,5.23(2.47)$ & $5,5.23(2.04)$ & $5,5.04(2.30)$ & 0.99 \\
\hline Digit symbols coding & $37.50,40.73(15.81)$ & $34,35.78(12.49)$ & $37,36.88(14.59)$ & 0.37 \\
\hline Similarities & $14,14.39(5.33)$ & $14,16.00(5.41)$ & $15,16.55(3.76)$ & 0.47 \\
\hline
\end{tabular}

$n$ number of patients

Median, mean and standard deviation values are presented

${ }^{\mathrm{a}}$ ANOVA test, ${ }^{\mathrm{b}}$ Kruskal-Wallis test

schizophrenia course and symptomatology, as well as with cognitive functioning has not been shown so far. We have found that elevated IL-6 level is associated with schizophrenia, that is in line with the results of previous metaanalyses $[2,4]$. We have not confirmed the influence of the IL6 -174G/C polymorphism on IL-6 level in patients with schizophrenia that was shown in one study [10]. Discrepancies between these results may be due to the fact that the participants of our study were relatively younger $(38.99 \pm 10.2$ vs. $46 \pm 9.8$ years), with earlier age of psychosis onset $(25.20 \pm 6.7$ vs. $24.3 \pm 8.1$ years $)$ and different ethnicities (Polish vs. Armenian). Finally, in our study we have controlled for the variables that may influence the relationship between the IL6 -174G/C polymorphism and IL-6 levels, such as age, gender, chlorpromazine equivalent, illness duration, cigarette smoking and BMI.

We have not shown the influence of the IL6 -174G/C polymorphism on the mode of onset, on the course of the disorder or on any single symptom described by OPCRIT checklist. However, -174GG homozygotes had significantly higher severity of positive symptoms in comparison with -174CC homozygotes. Interestingly, there was an increase in the level of positive symptoms with each $-174 \mathrm{G}$ allele. So far, there is one report showing the association between $3^{\prime}$-UTR $I L-6$ gene polymorphism with the positive symptom dimension in schizophrenia [37]. We have not found any correlation between serum IL-6 level 
Table 5 Correlations between clinical, demographic and cognitive correlates with plasma hsCRP and IL-6 levels in schizophrenia patients
Significant associations were marked in bold characters ( $p$ value $<0.05,2$-tailed)

* Significant correlations after the application of Bonferroni correction $(p<0.00147)$

\begin{tabular}{|c|c|c|}
\hline Clinical correlates & hsCRP & IL-6 \\
\hline \multicolumn{3}{|l|}{ Psychopathology } \\
\hline PANSS—positive symptoms subscale & $r=-0.14, p=0.20$ & $r=-0.05, p=0.66$ \\
\hline PANSS—negative symptoms subscale & $r=0.01, p=0.94$ & $r=0.15, p=0.23$ \\
\hline PANSS_-general symptoms subscale & $r=-0.12, p=0.28$ & $r=-0.04, p=0.73$ \\
\hline PANSS—depression item score & $r=-0.06, p=0.60$ & $r=0.19, p=0.10$ \\
\hline SAPS & $r=-0.03, p=0.78$ & $r=-0.05, p=0.66$ \\
\hline SANS & $r=-0.05, p=0.67$ & $r=0.15, p=0.22$ \\
\hline \multicolumn{3}{|l|}{ Cognitive tasks } \\
\hline TMT, part A & $r=0.09, p=0.39$ & $r=0.38, \boldsymbol{p}=\mathbf{0 . 0 0 1} *$ \\
\hline TMT, part B & $r=0.19, p=0.09$ & $r=0.48, \boldsymbol{p}=\mathbf{0 . 0 0 1} *$ \\
\hline TMT, part A- TMT, part B & $r=0.19, p=0.09$ & $r=0.34, \boldsymbol{p}=\mathbf{0 . 0 0 5}$ \\
\hline Stroop, congruent & $r=0.06, p=0.58$ & $r=0.27, \boldsymbol{p}=\mathbf{0 . 0 2 4}$ \\
\hline Stroop, incongruent & $r=0.17, p=0.13$ & $r=0.34, \boldsymbol{p}=\mathbf{0 . 0 0 5}$ \\
\hline RAVLT, first immediate recall & $r=-0.38, \boldsymbol{p}<\mathbf{0 . 0 0 1}^{*}$ & $r=-0.37, \boldsymbol{p}=\mathbf{0 . 0 0 2}$ \\
\hline RAVLT, second immediate recall & $r=-0.33, \boldsymbol{p}<\mathbf{0 . 0 0 1 *}$ & $r=-0.31, \boldsymbol{p}=\mathbf{0 . 0 0 9}$ \\
\hline RAVLT, third immediate recall & $r=-0.32, \boldsymbol{p}=\mathbf{0 . 0 0 3}$ & $r=-0.40, \boldsymbol{p}=\mathbf{0 . 0 0 1} *$ \\
\hline RAVLT, fourth immediate recall & $r=-0.34, \boldsymbol{p}=\mathbf{0 . 0 0 2}$ & $r=-0.39, \boldsymbol{p}=\mathbf{0 . 0 0 1} *$ \\
\hline RAVLT, fifth immediate recall & $r=-0.29, \boldsymbol{p}=\mathbf{0 . 0 0 7}$ & $r=-0.37, \boldsymbol{p}=\mathbf{0 . 0 0 1} *$ \\
\hline RAVLT, inference & $r=-0.15, p=0.170$ & $r=-0.25, \boldsymbol{p}=\mathbf{0 . 0 3 7}$ \\
\hline RAVLT, delayed recall & $r=-0.23, \boldsymbol{p}=\mathbf{0 . 0 4 9}$ & $r=-0.28, \boldsymbol{p}=\mathbf{0 . 0 2 4}$ \\
\hline RAVLT, recognition & $r=-0.33, \boldsymbol{p}=\mathbf{0 . 0 0 4}$ & $r=-0.36, \boldsymbol{p}=\mathbf{0 . 0 0 3}$ \\
\hline Verbal fluency, F words & $r=0.16, p=0.162$ & $r=-0.23, p=0.059$ \\
\hline Verbal fluency, A words & $r=-0.01, p=0.927$ & $r=-0.29, \boldsymbol{p}=\mathbf{0 . 0 1 4}$ \\
\hline Verbal fluency, S words & $r=0.16, p=0.163$ & $r=-0.17, p=0.156$ \\
\hline Verbal fluency, FAS total score & $r=0.11, p=0.329$ & $r=-0.31, \boldsymbol{p}=\mathbf{0 . 0 1 1}$ \\
\hline Verbal fluency, K words & $r=0.07, p=0.550$ & $r=-0.22, p=0.087$ \\
\hline Verbal fluency, supermarket & $r=0.11, p=0.343$ & $r=0.13 p=0.289$ \\
\hline Forward digit span & $r=-0.01, p=0.920$ & $r=-0.27, \boldsymbol{p}=\mathbf{0 . 0 2 6}$ \\
\hline Backward digit span & $r=-0.04, p=0.730$ & $r=-0.17, p=0.164$ \\
\hline Digit symbol coding & $r=-0.19, p=0.098$ & $r=-0.45, \boldsymbol{p}<\mathbf{0 . 0 0 1} *$ \\
\hline Similarities & $r=-0.02, p=0.842$ & $r=0.48, p=0.149$ \\
\hline \multicolumn{3}{|l|}{ Demographic and clinical correlates } \\
\hline Age & $r=0.11, p=0.31$ & $r=0.26, p=0.220$ \\
\hline BMI & $r=0.12, p=0.505$ & $r=0.26, p=0.062$ \\
\hline Pack-year index & $r=0.05, p=0.781$ & $r=0.09, p=0.523$ \\
\hline Chlorpromazine equivalent & $r=0.32, \boldsymbol{p}=\mathbf{0 . 0 0 9}$ & $r=0.57, \boldsymbol{p}<\mathbf{0 . 0 0 1 *}$ \\
\hline Illness duration & $r=0.19, p=0.073$ & $r=0.30, p=\mathbf{0 . 0 0 8}$ \\
\hline
\end{tabular}

and schizophrenia psychopathology. Previous studies have revealed a positive relationship between plasma IL-6 and the severity of positive symptoms in subjects with ARMS [5] and veterans with schizophrenia [38]. There is also one study showing a positive correlation between serum IL-6 and the severity of negative symptoms in drug-naïve schizophrenia males [39]. However, the vast majority of studies have not confirmed these findings [2, 4].

To the best of our knowledge, this is the first study investigating the influence of the IL6 -174G/C polymorphism together with serum IL-6 and hsCRP levels on cognition in schizophrenia patients. We have found no significant differences in cognitive performance with respect to the IL6 $-174 \mathrm{G} / \mathrm{C}$ polymorphism. However, we have found that higher IL-6 level is associated with impairment in cognitive functioning in terms of visual attention (Stroop test, TMT-A), visuomotor processing speed (Digit Symbol Coding, TMT-A), memory (Digit Span Forward, RAVLT), semantic memory (Verbal Fluency), working memory and task-switching ability (TMTB), as well as executive control function (the difference between TMT-B and TMT-A score). In turn, hsCRP level was associated with worse verbal memory performance (RAVLT). Importantly, the correlations of IL-6 level with 
Fig. 1 The comparison of hsCRP and IL-6 ( $p>0.05$ and $p=0.01$, respectively) levels among patients with different course of schizophrenia (multiple episodes with good or partial recovery between episodes, continuous chronic illness, continuous chronic illness with deterioration)

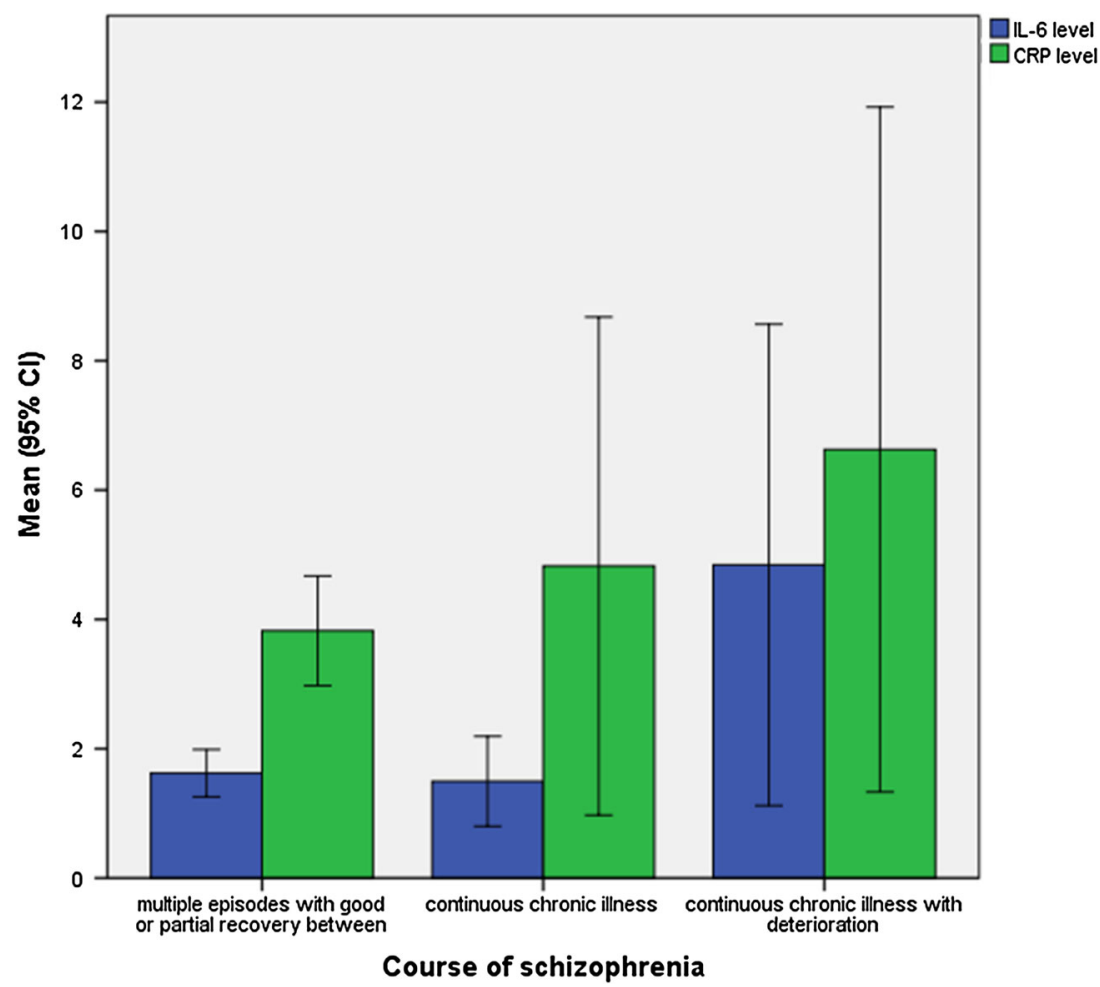

Table 6 Associations between cognitive tests score and serum IL-6 and hsCRP after adjustment for age, education level, number of years of completed education, illness duration, total positive and negative syndrome scale (PANSS) score

\begin{tabular}{llll}
\hline Cognitive tasks & hsCRP & $p$ & IL6 \\
\hline RAVLT immediate recall-total score & $-0.13(-0.26-0.01)$ & 0.06 & $-0.05(-0.10-0.01)$ \\
RAVLT, distraction & $-0.26(-0.81-0.28)$ & 0.34 & $-0.093(-0.37-0.12)$ \\
RAVLT, delayed recall & $-0.13(-0.60-0.05)$ & 0.56 & $-0.10(0 .-0.32-0.12)$ \\
RAVLT, recognition & $-0.15(-0.48$ to -0.18$)$ & 0.36 & $-0.09(-0.26-0.08)$ \\
Digit symbols coding & $-0.58(-0.19-0.75)$ & 0.39 & $-0.62(-0.11-0.16)$ \\
\hline
\end{tabular}

Significant associations were marked in bold characters $(p$ value $<0.05$, 2-tailed)

visual attention, task-switching ability (TMT-A and TMTB), visuomotor processing speed (TMT-A and Digit Symbol Coding), memory performance (RAVLT) and the correlation of hsCRP with memory performance (RAVLT) remained significant after the application of restrictive Bonferroni correction. After adjustment for possible confounders, such as age, education, illness duration, psychopathology and antipsychotic treatment, both hsCRP and IL-6 were related to worse cognitive performance with respect to immediate memory span (RAVLT learning summary score), while IL-6 level was additionally associated with lower score on visuomotor processing speed (Digit Symbol Coding task).

Notably, RAVLT learning summary score is widely used and has good test-retest reliability and has been shown to discriminate memory impairment from memory intact patients [40]. Lower RAVLT scores in patients with schizophrenia have been reported repeatedly both in drug naive [41], as well as in patients during long-term antipsychotic treatment [42]; however, our study is the first to show the association of the poorer performance on RAVLT with immune biomarkers. So far, a positive association between immediate memory impairment and IL-6 level has been reported in other patients, including older people [43], middle-aged adults [16] and patients with recurrent major depressive disorder [23].

Digit Symbol Coding task has been reported to be a measure differentiating schizophrenia patients from healthy controls, low- and high-risk relatives of schizophrenia patients from healthy controls and unaffected relatives from schizophrenia subjects [44]. Apart from its discriminative value, Digit Symbol Coding task may predict poor outcome and functional disability in schizophrenia [44, 45]. Furthermore, IL-6 level has been found to predict 
worse cognitive performance in Digit Symbol Coding test in the elderly [46] and type 2 diabetes elders [47].

Our results confirm reports from previous studies showing that CRP level is increased in schizophrenia patients [48, 49], including drug-naïve individuals [50]. The influence of CRP level on cognition, reported in our study, corresponds with the results obtained by Dickerson and colleagues [25, 51]. Authors found that CRP level negatively correlates with the overall cognitive functioning assessed by Repeatable Battery for the Assessment of Neuropsychological Status (RBANS) in schizophrenia patients [52], as well as with total cognitive performance and specific RBANS domains including attention, immediate memory and language in bipolar disorder patients [53]. Notably, Dickerson et al. [25] also failed to find a significant correlation between CRP level and psychopathology evaluated in PANSS, although the previous study by Fan et al. [54] indicated that CRP level is associated with higher severity of negative symptoms, general psychopathology and total PANSS score. We have found a positive correlation between IL-6 level and illness duration along with significantly higher levels of IL-6 in schizophrenia patients with chronic course of the disorder with deterioration. These findings corroborate previous studies showing the positive association between IL-6 and illness duration [7, 39] and higher IL-6 in patients with deficit schizophrenia [50]. Furthermore, it has been found that IL6 level positively correlates with duration of untreated psychosis [55]. Together with the fact that we have found the relationship between higher IL- 6 levels and cognitive decline in schizophrenia, it could be inferred that IL-6 may serve as a potential inflammatory biomarker accompanying neurodegenerative processes leading to cognitive deterioration in schizophrenia.

Notably, our study has some limitations that should be addressed. A possible limitation is a small sample size. However, our sample size is similar to that from the only study looking into correlations between the IL6 -174G/C polymorphism and IL-6 level in schizophrenia patients from Armenia [10]. In addition, the number of patients included in our study is comparable to the sample sizes that are commonly chosen for the studies on serum cytokines levels and cognitive functions in psychiatric disorders. Another limitation is a clinical heterogeneity of the patients included in the study (inpatients during the recovery from acute psychosis and stable outpatients). However, this approach allowed us to analyze cognitive impairments with regard to the wider spectrum of psychopathology severity and underlying subthreshold inflammation. Finally, we have not assessed cognitive functioning in healthy controls. Therefore, we cannot determine as to whether obtained correlations between IL-6 level and cognitive performance are specific for schizophrenia patients. Nevertheless, our results indicate that elevated IL-6 level may play additional role in the development of cognitive deficits described in schizophrenia and may further contribute to deterioration observed in the course of the disorder.

Our results indicate that elevated IL-6 in schizophrenia patients does not occur due to genetic variation in its gene. However, the IL6 $-174 \mathrm{G} / \mathrm{C}$ polymorphism may affect the severity of positive symptoms. In turn, cognitive impairments observed in schizophrenia might be the consequence of subclinical inflammation manifested in elevated hsCRP and IL-6 serum levels. Correlations between serum IL-6 level, illness duration and course of the disorder are in line with the notion that schizophrenia is a progressive disorder with low-grade inflammation, underlying its pathophysiology followed by cognitive decline.

Acknowledgments We are deeply grateful to all patients and healthy controls participating in this study. This work was supported by research grant "IL-2, IL-6, IFN-gamma and TGF-beta gene polymorphism in patients with schizophrenia" awarded by Ministry of Science and Higher Education, Grant Number N N402 465237.

Conflict of interest None to declare.

Open Access This article is distributed under the terms of the Creative Commons Attribution License which permits any use, distribution, and reproduction in any medium, provided the original author(s) and the source are credited.

\section{References}

1. Simpson RJ, Hammacher A, Smith DK, Matthews JM, Ward LD (1997) Interleukin-6: structure-function relationships. Protein Sci 6(5):929-955. doi:10.1002/pro.5560060501

2. Potvin S, Stip E, Sepehry AA, Gendron A, Bah R, Kouassi E (2008) Inflammatory cytokine alterations in schizophrenia: a systematic quantitative review. Biol Psychiatry 63(8):801-808. doi:10.1016/j.biopsych.2007.09.024

3. Zalcman S, Green-Johnson JM, Murray L, Nance DM, Dyck D, Anisman H, Greenberg AH (1994) Cytokine-specific central monoamine alterations induced by interleukin-1, -2 and -6 . Brain Res 643(1-2):40-49

4. Miller BJ, Buckley P, Seabolt W, Mellor A, Kirkpatrick B (2011) Meta-analysis of cytokine alterations in schizophrenia: clinical status and antipsychotic effects. Biol Psychiatry 70(7):663-671. doi:10.1016/j.biopsych.2011.04.013

5. Stojanovic A, Martorell L, Montalvo I, Ortega L, Monseny R, Vilella E, Labad J (2014) Increased serum interleukin-6 levels in early stages of psychosis: associations with at-risk mental states and the severity of psychotic symptoms. Psychoneuroendocrinology 41:23-32. doi:10.1016/j.psyneuen.2013.12.005

6. Lin A, Kenis G, Bignotti S, Tura GJ, De Jong R, Bosmans E, Pioli R, Altamura C, Scharpe S, Maes M (1998) The inflammatory response system in treatment-resistant schizophrenia: increased serum interleukin-6. Schizophr Res 32(1):9-15

7. Ganguli R, Yang Z, Shurin G, Chengappa KN, Brar JS, Gubbi AV, Rabin BS (1994) Serum interleukin-6 concentration in schizophrenia: elevation associated with duration of illness. Psychiatry Res 51(1):1-10 
8. Terry CF, Loukaci V, Green FR (2000) Cooperative influence of genetic polymorphisms on interleukin 6 transcriptional regulation. J Biol Chem 275(24):18138-18144. doi:10.1074/jbc. M000379200

9. Fishman D, Faulds G, Jeffery R, Mohamed-Ali V, Yudkin JS, Humphries S, Woo P (1998) The effect of novel polymorphisms in the interleukin-6 (IL-6) gene on IL-6 transcription and plasma IL-6 levels, and an association with systemic-onset juvenile chronic arthritis. J Clin Investig 102(7):1369-1376. doi:10.1172/ JCI2629

10. Zakharyan R, Petrek M, Arakelyan A, Mrazek F, Atshemyan S, Boyajyan A (2012) Interleukin-6 promoter polymorphism and plasma levels in patients with schizophrenia. Tissue Antigens 80(2):136-142. doi:10.1111/j.1399-0039.2012.01886.x

11. Paul-Samojedny M, Kowalczyk M, Suchanek R, Owczarek A, Fila-Danilow A, Szczygiel A, Kowalski J (2010) Functional polymorphism in the interleukin-6 and interleukin-10 genes in patients with paranoid schizophrenia: a case-control study. Journal of molecular neuroscience : MN 42(1):112-119. doi:10. 1007/s12031-010-9365-6

12. Frydecka D, Misiak B, Beszlej JA, Karabon L, Pawlak-Adamska E, Tomkiewicz A, Partyka A, Jonkisz A, Kiejna A (2013) Genetic variants in transforming growth factor-beta gene (TGFB1) affect susceptibility to schizophrenia. Mol Biol Rep. doi:10.1007/ s11033-013-2662-8

13. Paul-Samojedny M, Owczarek A, Kowalczyk M, Suchanek R, Palacz M, Kucia K, Fila-Danilow A, Borkowska P, Kowalski J (2013) Association of interleukin 2 (IL-2), interleukin 6 (IL-6), and TNF-alpha (TNFalpha) gene polymorphisms with paranoid schizophrenia in a Polish population. J Neuropsychiatry Clin Neurosci 25(1):72-82. doi:10.1176/appi.neuropsych.12020021

14. Debnath M, Mitra B, Bera NK, Chaudhuri TK, Zhang YP (2013) Lack of association of IL-6 (-174 G > C) and TNF-alpha (-238 $\mathrm{G}>\mathrm{A})$ variants with paranoid schizophrenia in Indian Bengalee population. Cytokine 61(2):455-458. doi:10.1016/j.cyto.2012.10. 028

15. Liu YL, Liu CM, Fann CS, Yang WC, Chen YH, Tseng LJ, Liu SK, Hsieh MH, Hwang TJ, Chan HY, Chen JJ, Chen WJ, Hwu HG (2010) Genetic variants of IL-6 and its receptor are not associated with schizophrenia in Taiwan. Neurosci Lett 468(3):330-333. doi:10.1016/j.neulet.2009.11.026

16. Gimeno D, Marmot MG, Singh-Manoux A (2008) Inflammatory markers and cognitive function in middle-aged adults: the Whitehall II study. Psychoneuroendocrinology 33(10):1322-1334. doi:10.1016/j.psyneuen.2008.07.006

17. Marsland AL, Petersen KL, Sathanoori R, Muldoon MF, Neumann SA, Ryan C, Flory JD, Manuck SB (2006) Interleukin-6 covaries inversely with cognitive performance among middleaged community volunteers. Psychosom Med 68(6):895-903. doi:10.1097/01.psy.0000238451.22174.92

18. Simpson EE, Hodkinson CF, Maylor EA, McCormack JM, Rae G, Strain S, Alexander HD, Wallace JM (2013) Intracellular cytokine production and cognition in healthy older adults. Psychoneuroendocrinology 38(10):2196-2208. doi:10.1016/j.psy neuen.2013.04.007

19. Mooijaart SP, Sattar N, Trompet S, Lucke J, Stott DJ, Ford I, Jukema JW, Westendorp RG, de Craen AJ (2013) Circulating interleukin- 6 concentration and cognitive decline in old age: the PROSPER study. J Intern Med 274(1):77-85. doi:10.1111/joim. 12052

20. Heringa SM, van den Berg E, Reijmer YD, Nijpels G, Stehouwer CD, Schalkwijk CG, Teerlink T, Scheffer PG, van den Hurk K, Kappelle LJ, Dekker JM, Biessels GJ (2014) Markers of low-grade inflammation and endothelial dysfunction are related to reduced information processing speed and executive functioning in an older population - the Hoorn Study.
Psychoneuroendocrinology 40:108-118. doi:10.1016/j.psyneuen. 2013.11.011

21. Jordanova V, Stewart R, Davies E, Sherwood R, Prince M (2007) Markers of inflammation and cognitive decline in an AfricanCaribbean population. Int J Geriatr Psychiatry 22(10):966-973. doi:10.1002/gps.1772

22. Lekander M, von Essen J, Schultzberg M, Andreasson AN, Garlind A, Hansson LO, Nilsson LG (2011) Cytokines and memory across the mature life span of women. Scand J Psychol 52(3):229-235. doi:10.1111/j.1467-9450.2010.00865.x

23. Grassi-Oliveira R, Bauer ME, Pezzi JC, Teixeira AL, Brietzke E (2011) Interleukin-6 and verbal memory in recurrent major depressive disorder. Neuro Endocrinol Lett 32(4):540-544

24. Keefe RS, Harvey PD (2012) Cognitive impairment in schizophrenia. Handb Exp Pharmacol 213:11-37. doi:10.1007/978-3642-25758-2_2

25. Dickerson F, Stallings C, Origoni A, Boronow J, Yolken R (2007) C-reactive protein is associated with the severity of cognitive impairment but not of psychiatric symptoms in individuals with schizophrenia. Schizophr Res 93(1-3):261-265. doi:10. 1016/j.schres.2007.03.022

26. Muller N, Myint AM, Schwarz MJ (2012) Immunological treatment options for schizophrenia. Curr Pharm Biotechnol 13(8):1606-1613

27. Nitta M, Kishimoto T, Muller N, Weiser M, Davidson M, Kane JM, Correll CU (2013) Adjunctive use of nonsteroidal antiinflammatory drugs for schizophrenia: a meta-analytic investigation of randomized controlled trials. Schizophr Bull 39(6):1230-1241. doi:10.1093/schbul/sbt070

28. Sommer IE, de Witte L, Begemann M, Kahn RS (2012) Nonsteroidal anti-inflammatory drugs in schizophrenia: ready for practice or a good start? A meta-analysis. J Clin Psychiatry 73(4):414-419. doi:10.4088/JCP.10r06823

29. Muller N, Riedel M, Schwarz MJ, Engel RR (2005) Clinical effects of COX-2 inhibitors on cognition in schizophrenia. Eur Arch Psychiatry Clin Neurosci 255(2):149-151. doi:10.1007/ s00406-004-0548-4

30. McGuffin P, Farmer A, Harvey I (1991) A polydiagnostic application of operational criteria in studies of psychotic illness. Development and reliability of the OPCRIT system. Arch Gen Psychiatry 48(8):764-770

31. Woods SW (2003) Chlorpromazine equivalent doses for the newer atypical antipsychotics. J Clin Psychiatry 64(6):663-667

32. Rey A (1964) The clinical examination in psychology. University Press of France, Paris

33. Reitan RM (1955) The relation of the trail making test to organic brain damage. J Consult Psychol 19(5):393-394

34. Benton AL (1968) Differential behavioural effects in frontal lobe disease. Neuropsychologia 6:53-60

35. Kessler J, Denzler P, Markowitsch HJ (1988) Manual Demenz Test - Wrotproduktion ("Supermarktaufgabe). Dementznormen. 10

36. Jensen AR (1965) Scoring the stroop test. Acta Psychol 24(5):398-408

37. Liu YL, Liu CM, Fann CS, Yang WC, Chen YH, Tseng LJ, Liu SK, Hsieh MH, Hwang TJ, Chan HY, Chen JJ, Chen WJ, Hwu HG (2010) Genetic variants of IL-6 and its receptor are not associated with schizophrenia in Taiwan. Neurosci Lett 468(3):330-333. doi:10.1016/j.neulet.2009.11.026

38. Dimitrov DH, Lee S, Yantis J, Valdez C, Paredes RM, Braida N, Velligan D, Walss-Bass C (2013) Differential correlations between inflammatory cytokines and psychopathology in veterans with schizophrenia: potential role for IL-17 pathway. Schizophr Res 151(1-3):29-35. doi:10.1016/j.schres.2013.10.019

39. Kim YK, Kim L, Lee MS (2000) Relationships between interleukins, neurotransmitters and psychopathology in drug-free male schizophrenics. Schizophr Res 44(3):165-175 
40. Crane PK, Carle A, Gibbons LE, Insel P, Mackin RS, Gross A, Jones RN, Mukherjee S, Curtis SM, Harvey D, Weiner M, Mungas D (2012) Development and assessment of a composite score for memory in the Alzheimer's Disease Neuroimaging Initiative (ADNI). Brain Imaging Behav 6(4):502-516. doi:10. 1007/s11682-012-9186-Z

41. Manglam MK, Das A (2013) Verbal learning and memory and psychopathology in schizophrenia. Asian J Psychiatr 6(5):417-420. doi:10.1016/j.ajp.2013.05.009

42. Ekerholm M, Firus Waltersson S, Fagerberg T, Soderman E, Terenius L, Agartz I, Jonsson EG, Nyman H (2012) Neurocognitive function in long-term treated schizophrenia: a five-year follow-up study. Psychiatry Res 200(2-3):144-152. doi:10.1016/ j.psychres.2012.05.008

43. van den Kommer TN, Dik MG, Comijs HC, Jonker C, Deeg DJ (2010) Homocysteine and inflammation: predictors of cognitive decline in older persons? Neurobiol Aging 31(10):1700-1709. doi:10.1016/j.neurobiolaging.2008.09.009

44. Dickinson D, Ramsey ME, Gold JM (2007) Overlooking the obvious: a meta-analytic comparison of digit symbol coding tasks and other cognitive measures in schizophrenia. Arch Gen Psychiatry 64(5):532-542. doi:10.1001/archpsyc.64.5.532

45. Dickinson D (2008) Digit symbol coding and general cognitive ability in schizophrenia: worth another look? Br J Psychiatry 193(5):354-356. doi:10.1192/bjp.bp.108.049387

46. Rafnsson SB, Deary IJ, Smith FB, Whiteman MC, Rumley A, Lowe GD, Fowkes FG (2007) Cognitive decline and markers of inflammation and hemostasis: the Edinburgh Artery Study. J Am Geriatr Soc 55(5):700-707. doi:10.1111/j.1532-5415.2007. 01158.x

47. Marioni RE, Strachan MW, Reynolds RM, Lowe GD, Mitchell RJ, Fowkes FG, Frier BM, Lee AJ, Butcher I, Rumley A, Murray GD, Deary IJ, Price JF (2010) Association between raised inflammatory markers and cognitive decline in elderly people with type 2 diabetes: the Edinburgh Type 2 Diabetes Study. Diabetes 59(3):710-713. doi:10.2337/db09-1163
48. Miller BJ, Culpepper N, Rapaport MH (2013) C-reactive protein levels in schizophrenia: a review and meta-analysis. Clin Schizophr Relat Psychoses 7(4):223-230. doi:10.3371/CSRP.MICU. 020813

49. Dickerson F, Stallings C, Origoni A, Vaughan C, Khushalani S, Yang S, Yolken R (2013) C-reactive protein is elevated in schizophrenia. Schizophr Res 143(1):198-202. doi:10.1016/j. schres.2012.10.041

50. Garcia-Rizo C, Fernandez-Egea E, Oliveira C, Justicia A, Bernardo M, Kirkpatrick B (2012) Inflammatory markers in antipsychotic-naive patients with nonaffective psychosis and deficit vs. nondeficit features. Psychiatry Res 198(2):212-215. doi:10. 1016/j.psychres.2011.08.014

51. Dickerson F, Stallings C, Origoni A, Vaughan C, Khushalani S, Yang S, Yolken R (2013) C-reactive protein is elevated in schizophrenia. Schizophr Res 143(1):198-202. doi:10.1016/j. schres.2012.10.041

52. Dickerson F, Stallings C, Origoni A, Boronow J, Yolken R (2007) C-reactive protein is associated with the severity of cognitive impairment but not of psychiatric symptoms in individuals with schizophrenia. Schizophr Res 93(1-3):261-265. doi:10. 1016/j.schres.2007.03.022

53. Dickerson F, Stallings C, Origoni A, Vaughan C, Khushalani S, Yolken R (2013) Elevated C-reactive protein and cognitive deficits in individuals with bipolar disorder. J Affect Disord 150(2):456-459. doi:10.1016/j.jad.2013.04.039

54. Fan X, Pristach C, Liu EY, Freudenreich O, Henderson DC, Goff DC (2007) Elevated serum levels of C-reactive protein are associated with more severe psychopathology in a subgroup of patients with schizophrenia. Psychiatry Res 149(1-3):267-271. doi:10.1016/j.psychres.2006.07.011

55. Dunjic-Kostic B, Jasovic-Gasic M, Ivkovic M, Radonjic NV, Pantovic M, Damjanovic A, Poznanovic ST, Jovanovic A, Nikolic T, Petronijevic ND (2013) Serum levels of interleukin-6 and tumor necrosis factor-alpha in exacerbation and remission phase of schizophrenia. Psychiatria Danubina 25(1):55-61 